\title{
NOVAS E VELHAS QUESTÕES EM TORNO DA PRESCRIÇÃO TRABALHISTA
}

\author{
Estêvão Mallet \\ Professor Associado de Direito do Trabalho da Faculdade \\ de Direito da Universidade de São Paulo
}

\begin{abstract}
Resumo:
A prescrição constitui tema de repleto de controvérsias no Direito do Trabalho. Importa, por isso, considerá-lo mais detidamente, especialmente em dois pontos. O primeiro relaciona-se com a recente alteração da Constituição, que tornou suscetível de prescrição, durante a vigência do contrato de trabalho, os créditos do trabalhador rural. A inovação suscita interessantes questões de direito transitório. $\mathrm{O}$ segundo diz respeito à prescrição da pretensão executiva, até hoje malresolvido pela jurisprudência, e que tem recebido tratamento não-harmônico em doutrina.
\end{abstract}

\begin{abstract}
:
Labor law prescription constitutes a theme replete with contraversy. It therefore should be considered more closely particularly concerning two items: The first one relates to the recent alteration of the Constitution which rendered susceptible to prescription during labor contract validity, credits of rural workers. This novelty engenders interesting inquiries of transitory jurisprudence. The second item relates to the prescription of executive arrogation which until the present date has been badly dealt with by jurisprudence and that has received non-coherent handling in precept.
\end{abstract}

Unitermos: prescrição; contrato de trabalho; trabalhador rural; execução; prescrição intercorrente.

Sumário:

1. Introdução;

2. Nova regulamentação da prescrição aplicável à relação de emprego rural; 
3. Transcurso da prescrição durante a vigência do contrato de trabalho;

4. Constitucionalidade da Emenda n. 28;

5. Aplicação no tempo da nova regra sobre prescrição;

6. Prescrição e execução;

7. Prescrição da pretensão executiva em matéria trabalhista;

8. Prescrição da pretensão executiva e prescrição intercorrente;

9. Prazo de prescrição da pretensão executiva trabalhista.

\section{Introdução.}

Poucos temas em matéria trabalhista suscitaram e ainda suscitam tantas e tão-prolongadas controvérsias como a prescrição. O passar do tempo, que, no instituto da prescrição, serve para dotar de maior segurança as relações jurídicas, só ampliou e aprofundou essas controvérsias, e isto por diferentes razões.

De um lado, pouca atenção dedicou o legislador à matéria, considerandoa de modo esparso, tópico e mal-sistematizado, deixando lacunas em toda parte. Como se não bastasse, a intervenção legislativa, quando se manifesta, apresenta-se oscilante e até mesmo contraditória. Alguns prazos são ampliados, como se deu, após a Constituição de 1988, com a prescrição aplicável à relação de emprego do trabalhador urbano, durante a vigência do contrato de trabalho, enquanto outros são encurtados, como acaba de ocorrer com a prescrição na relação de emprego rural. Ademais, a jurisprudência não-raro mostra-se incerta e vacilante. Soluções consagradas, como a prescrição de trinta anos para as contribuições do FGTS ou a possibilidade de argüir a prescrição mesmo após a defesa, são postas em causa.

Em síntese, muitos aspectos da prescrição trabalhista mereceriam ser aqui considerados. Abordar todos, porém, ultrapassaria os limites propostos para o presente estudo. Em conseqüência, apenas dois serão tratados. O primeiro relacionado com a Emenda Constitucional n. 28, por sua atualidade. O segundo atinente à prescrição da pretensão executiva, diante de sua importância prática e, ao mesmo tempo, escassa consideração teórica.

2. Nova regulamentação da prescrição aplicável à relação de emprego rural.

Com a Emenda Constitucional n. 28, de 25 de maio de 2000, modificouse o regime da prescrição aplicável à relação de emprego rural. Se antes não fluía a 
prescrição durante a vigência do contrato de trabalho, apenas facultando-se ao empregador comprovar periodicamente o cumprimento das obrigações trabalhistas, ' agora a prescrição se consuma após cinco anos, enquanto em vigor o vínculo de emprego, de acordo com a nova redação dada ao art. $7^{\circ}$, inciso XXIX, da Constituição, de teor seguinte: "ação, quanto a créditos resultantes das relações de trabalho, com prazo prescricional de cinco anos para os trabalhadores urbanos e rurais, até o limite de dois anos após a extinção do contrato de trabalho" Essa alteração deve ser considerada não apenas sob o ponto de vista de sua oportunidade e validade como, igualmente, sob o ponto de vista de sua aplicação no tempo, enfrentando-se os delicados problemas de direito transitório dela decorrentes.

3. Transcurso da prescrição durante a vigência do contrato de trabalho.

A fluência do prazo prescricional faz supor possa o titular do direito "exigir o ato, ou a omissão", 2 Antes da exigibilidade não há prescrição, ${ }^{3}$ como evidencia, aliás, a regra do art. 149, da CLT.

Em matéria trabalhista, porém, ainda que formalmente possa o empregado, verificada a lesão, de pronto exigir a reparação correspondente, se o fizer, colocará em risco, não sendo estável, a continuidade de seu contrato de trabalho. Por isso, melhor se amolda às peculiaridades da relação de emprego comum, inclusive e especialmente no meio rural, a fluência da prescrição somente depois de extinto o vínculo, como já dispunha a Lei n. 5.889/83, ${ }^{4}$ em diretriz mantida pela Constituição de 1988.

É a conclusão que se tira, aliás, do Direito Comparado. Em Portugal, por exemplo, dispõe o art. 38 , n. 1, da Lei do Regime Jurídico do Contrato Individual de Trabalho: "Todos os créditos resultantes do contrato de trabalho e da sua violação ou cessação, quer pertencentes à entidade patronal, quer pertencentes ao trabalhador, extinguem-se por prescrição, decorrido um ano a partir do dia seguinte àquele em que cessou o contrato de trabalho..." Interpretando esse dispositivo, ressaltou a Relação de Lisboa que o termo inicial do prazo, vinculado à extinção do contrato de

1. Arts. 7o, inciso XXIX, alinca "b" c 233, da Constituição.

2. Pontes de Miranda, Tratado de Dircito Privado, Rio de Janciro, Borsoi, 1955, v. 6, p. I14.

3. Josscrand, Cours de Droit Civil positiffirançais, Paris, Sircy, 1933, II, p. 571.

4. Art. 10. 
trabalho, coincide com "a cessação da situação de subordinação que implicaria o receio do trabalhador, limitativo do livre exercicio dos seus direitos" ${ }^{5}$ Nessa linha, a doutrina assinala que, durante a vigência do contrato, "a situação de dependência do trabalhador não lhe permite, presumivelmente, exercer em pleno os seus direitos" "

A idêntico resultado se chegou no Direito italiano, mesmo sendo preciso, para tanto, suplantar a regulamentação legal positivada. De fato, com a Sentença n. 63, de 10 de junho de 1966, a Corte Constitucional italiana afirmou a inconstitucionalidade da regra do art. 2.948, n. 4, do Código Civil, que, de modo expresso, estabelecia o transcurso da prescrição durante a vigência do contrato de trabalho. Considerou-se esse critério incompatível com a irrenunciabilidade dos direitos trabalhistas, afirmada pelo art. 36, da Constituição. ${ }^{7}$ Em consequiência, com o julgamento da Corte Constitucional, apenas depois de extinto o contrato passou a iniciar-se o prazo prescricional, salvo em se tratando, como explicitou ainda a mesma Corte Constitucional, na sentença n. 174, de 12 de dezembro de 1972, de relação de emprego insuscetível de denúncia imotivada pelo empregador. A despeito de toda controvérsia suscitada por tais pronunciamentos, ${ }^{8}$ reconheceu a doutrina a coerência da solução que acabou se impondo, pois, como nota Luisa Galantino, "è certamente incongruo che il legislatore, durante il rapporto di lavoro, tuteli il lavoratore in caso di rinuncia ad un proprio diritto (art. 2113 c. c.) e non per un atto di disposizine indireta del diritto steso, quale è il suo mancato esercizio nel termine prescrizionale". ?

Deve-se registrar, finalmente, que, modificação próxima da que ora se fez na legislação brasileira, quando promovida na legislação uruguaia, foi criticada pela doutrina, sendo considerada nociva. ${ }^{10}$

Em síntese, não se mostra positiva a inovação trazida pela Emenda Constitucional n. 28.

5. Acórdão no Recurso n. 84 , de 25.07 .84 in Abílio Neto, Contrato de Trabalho notas práticas, Lisboa, Pctrony, 1990, p. 159.

6. António Lemos Montciro Fernandes, Dircito do Trabalho, Lisboa, Almedina, 1999, p. 464.

7. Cf. Vezio Crisafulli c Livio Paladin, Commentario breve alla Costituzione, Padova, CEDAM, 1990, p. 244.

8. A propósito, com vasta indicação de doutrina sobrc o tema, Renato Corrado, Trattato di Diritto del Lavoro, Torino, UTET, 1969, volume terzo, p. 1.021 c segs., c Carlo Smuraglia, La prescrizione dei crediti di lavoro in Nuovo Trattato di Diritto del Lavoro, Padova, CEDAM, 1971, v. II, p. 788 c ss.

9. Diritto del Lavoro, Torino, Giappichelli, 1997, p. 689. Analogamente, Luisa Riva Sanscverino, Diritto del Lavoro, Padova, CEDAM, 1971, p. 517.

10. Amćrico Plá Rodrigucz, Principios de Dircito do Traballıo, São Paulo, LTr, 2000, pp. 219-238. 


\section{Constitucionalidade da Emenda n. 28}

De todo modo, não há como afirmar a inconstitucionalidade da Emenda Constitucional n. 28. Mesmo reconhecida a possibilidade de controle de constitucionalidade de norma de revisão constitucional ou de emenda à Constituição, como já é hoje largamente aceito," aos direitos sociais, ainda que considerados fundamentais, não se conferiu a particular rigidez atribuída aos direitos individuais, insuscetíveis de abolição. ${ }^{12}$ Por isso, a redução dos prazos de prescrição durante a vigência do contrato de trabalho - indesejável que seja - não ofende a regra limitativa do art. $60, \S 4^{\circ}$, inciso IV, da Constituição. Ofensa haveria, isso sim, se se estabelecesse prazo excessivamente curto, de modo a inviabilizar o efetivo direito de tutela jurisdicional, em desacordo com a garantia do art. $5^{\circ}$, inciso XXXV, da Constituição, ${ }^{13}$ o que não é o caso.

Torna-se necessário, portanto, definir os limites de aplicação no tempo do novo regime de prescrição incidente sobre o contrato de trabalho do empregado rural.

\section{Aplicação no tempo da nova regra sobre prescrição}

Alterado apenas o prazo prescricional aplicável aos contratos de trabalho em curso, é evidente que os contratos extintos antes da promulgação da Emenda Constitucional n. 28 ficam sujeitos apenas ao direito anterior. Ainda que tenham os contratos vigorado por período superior ao que, de acordo com o direito novo, tornaria consumada a prescrição, será a matéria regulada inteiramente pelos arts. $7^{\circ}$ : inciso XXIX, alínea "b" e, se for o caso, 233, da Constituição. A lei nova não apanha relação

11. Na jurisprudência do Supremo Tribunal Fedcral: "Uma Emenda Constitucional, cmanada, portanto, de Constituinte derivada, incidindo $\mathrm{cm}$ violação a Constituição originária, pode ser declarada inconstitucional, pelo Supremo Tribunal Federal, cuja função precipua e de guarda da Constituição (art. 102, I, "a", da C.F.)"(STF - Pleno, ADIn n. 939-DF, Rel. Min. Sydncy Sanches, julg. cm 15.12.93 in DJU de 18.03.94, p. 5.165). Em doutrina, entre tantos, Jorge Miranda, Manual de Dircito Constitucional, Coimbra, Coimbra Editora, 1996, tomo II, p. 316 c scgs., Vezio Crisafulli, Lezioni di Diritto Costituzionale, Padova, CEDAM, 1974, II, 2, p. 82 c segs. c, ainda mais amplamente, o conhecido texto de Otto Bachof, Normas constitucionais inconstitucionais?, Coimbra, Atlântida, 1977, passim.

\section{Constituição, art. $60, \S 4^{4}$, inciso IV.}

13. Foi justamente por ofender a garantia de acesso à jurisdiçào que a Corte Constitucional italiana repeliu, com a Sentença n. 85, de 1968, o prazo excessivamente curto estabclecido no Real Decreto n. 1765, de 1935, para apresentação de pedido de recebimento de prestação decorrente de acidente do traballo. Sobre o tcma, com indicação ainda de outros desdobramentos da garantia de accsso à jurisdição, no tocantc a prazos para excrcício de dircitos, Ferruccio Tommasco, Appunti di Diritto Processuale Civile, Torino, Giappichclli, 1995, pp. 195/199. 
jurídica já exaurida ao tempo de sua edição, ${ }^{14}$ consoante sublinhou o Tribunal Superior do Trabalho, ao negar a exigibilidade da multa de $40 \%$ sobre o saldo do FGTS para as dispensas imotivadas ocorridas antes da promulgação da Constituição de 1988. ${ }^{15}$

Do mesmo modo, os contratos de trabalho celebrados após a Emenda Constitucional n. 28 desde logo ficam sujeitos à nova regra sobre prescrição, nenhuma relação guardando com o direito anterior.

Já para os contratos em vigor ao tempo da promulgação da Emenda Constitucional n. 28 diversas alternativas se apresentam.

De um lado haveria a possibilidade de exclui-los simplesmente da nova disciplina legal, fazendo com que apenas os contratos de trabalho celebrados após a Emenda Constitucional n. 28 ficassem expostos à prescrição qüinqüenal. Os contratos em vigor, ao contrário, continuariam sujeitos ao critério anterior, iniciando-se o transcurso da prescrição somente depois de extinta a relação de emprego. Essa solução, fundada na idéia de que "soumettre le contrat à la loi nouvelle ce serait modifier les bases sur la foi desquelles les parties ont édifié leur accord" " não se mostra, todavia, aceitável. Nada há na Emenda Constitucional n. 28 restringindo sua aplicação apenas aos novos contratos de trabalho. Ademais, o contrato de trabalho, como contrato de trato sucessivo que é, fica sujeito à lei nova que se edite durante sua vigência, nos termos do art. 921, da CLT, salvo no que toca aos direitos já adquiridos, aos atos jurídicos perfeitos e à coisa julgada, não gerando o mero prazo prescricional, enquanto não exaurido, aquisição de direito. ${ }^{17}$ Nas palavras de Aubry e Rau, "la prescription ne donne de droit acquis que lorsqu' elle est définitivement accomplie" I8 Tanto é verdade que, ampliado o prazo prescricional para o trabalhador urbano, com a Constituição de 200.

14. Oscar Tenorio, Lci de Introduçào ao Código Civil Brasilciro, Rio de Janciro, Borsoi, 1955, p.

15. Cf., a propósito, TST - 4" T., RR 217.150, Rcl. Min. Galba Vclloso, Ac. n. 3.470 in D.J.U. de 21.06.96, p. 22.604 c, ainda, de modo mais cxplicito, o scguinte acórdão: "FGTS. Multa. Irrctroatividadc. Decisório regional que ferc o principio da irretroatividade das lcis ao determinar a incidência de dispositivo constitucional art. 10 do Ato das Disposiçõcs Constitucionais Transitórias $\mathrm{cm}$ rclação a dircito já satisfeito sob a ćgide da lcgislação vigentc à ćpoca cm que lcvantado valor do FGTS - março de 1987"(TST -4" T., RR n. 45.250/92, Rcl. Min. Galba Velloso, Ac. n. 3.112 in D.J.U. de 17.12.93, p. 28.304).

16. François Terré, Introduction générale au droit, Paris, Dalloz, 1998, p. 458.

17. Amplamentc, Paul Roubier, Le Droit Transitoire, Paris, Dalloz, 1960, p. 297.

18. Cours de droit civil français, Paris, Marchal \& Billard, 1935, tome deuxieme, $\$ 215$ bis, p. 497. No mesmo sentido, Carvalho Santos, Codigo Civil Brasilciro Interpretado, Rio de Janciro, Frcitas Bastos, 1937, v. I, p. 54. 
1988, mesmo os contratos já em curso passaram a observar a nova disciplina normativa, apenas não se apagando a prescrição já consumada. ${ }^{19}$

Solução oposta consistiria em aplicar de imediato a nova regra, considerando-se, para definição do lapso prescricional a ser observado, inclusive o tempo transcorrido antes da promulgação da Emenda Constitucional n. 28. Tal solução, sobre envolver aplicação retroativa de norma legal, ${ }^{20}$ algo condenado desde o Direito Romano, ${ }^{21}$ não pode ser adotada, quando se reduz o prazo prescricional ou se faz suscetível de prescrição o que, até então, não o era. De fato, sujeitar às regras da lei nova o tempo transcorrido, durante a vigência da lei antiga, significaria atribuir a esse tempo valor que não lhe era conferido antes, ${ }^{22}$ possibilitando, outrossim, se consumasse instantaneamente a prescrição de toda e qualquer pretensão exigível em prazo superior ao da nova regulamentação, o que evidentemente se deve afastar.

Solução intermediária consistiria em aplicar a lei nova apenas para regular o tempo transcorrido após a reforma legislativa, subordinando à lei anterior todo o lapso de tempo transcorrido antes dessa reforma. Contudo, tendo em vista não haver, no sistema anterior à Emenda Constitucional n. 28, prescrição durante a vigência do contrato de trabalho, a adoção desse critério, que combina duas diferentes legislações para reger a mesma relação jurídica, levaria a inaceitável paradoxo. Isso faria com que pretensões exigiveis há mais tempo, quando em vigor a legislação anterior, não prescrevessem, ao passo que outras pretensões, exigíveis há menos tempo, depois de editado o novo direito, poderiam já estar prescritas.

Na verdade, a melhor solução para as dificuldades suscitadas pela Emenda Constitucional n. 28 está em aplicar o novo prazo a todos os contratos em vigor, considerando-se, no entanto, apenas o tempo transcorrido após a reforma legislativa, critério preconizado, aliás, pela doutrina, nacional ${ }^{23}$ e estrangeira, ${ }^{24}$ bem como pela

19. Enunciado n. 308, do Tribunal Supcrior do Trabalho.

20. Planiol c Ripert, Traité élémentaire de Droit Civil, Paris, LGDJ, 1932, tome premier, p. 103.

21. A propósito, Rudolf von Jhcring, L'esprit du droit roman, Paris, Marcscq, 1836, tome deuxième, p. 75.

22. Francesco Fcrara, Trattato di Diritto Civile Italiano, Roma, Athenaeum, 1921, p. 275.

23. Eduardo Espinola c Eduardo Espinola Filho, A Lci dc Introdução ao Código Civil Brasilciro, Rio de Janciro, Frcitas Bastos, 1943, v. 1o, p. 479 c Luiz Frederico Carpenter, Manual do Codigo Civil Brasilciro, Rio de Janciro, Jacintho Ribciro dos Santos, 1929, v. IV, p. 596.

24. Paul Roubicr, Le Droit Transitoire cit., p. 300. 
jurisprudência da Corte de Cassação francesa. ${ }^{25}$ Assim, o tempo passado antes da Emenda Constitucional n. 28 não será considerado, evitando-se aplicação retroativa de no:ma legal. Somente a partir da promulgação da Emenda Constitucional n. 28 terá início o prazo de cinco anos da prescrição incidente sobre a relação jurídica em vigor. Passado esse prazo, porém, estarão prescritas todas as pretensões, cuja exigibilidade haja nascido há mais de cinco anos, ainda que antes da Emenda Constitucional n. 28.

Delimitado o âmbito de aplicação no tempo da Emenda Constitucional n. 28, resta agora tratar do segundo tema proposto, atinente à prescrição da pretensão executiva.

\section{Prescrição e execução.}

A execução não constitui mera fase do processo de conhecimento. Afirmação em contrário, por vezes ainda encontrada em doutrina ${ }^{26}$ e mesmo em um ou outro julgado, ${ }^{27}$ constitui reflexo do menor prestígio que no passado se tributava à execução, ${ }^{28}$ sem qualquer correspondência, no entanto, com o desenvolvimento hoje alcançado pela ciência processual.

De fato, a execução é ação autônoma, e não mero desdobramento ou continuação do processo de conhecimento. Em primeiro lugar, a atividade desenvolvida na execução não se confunde com a que é desenvolvida no processo de conhecimento. Neste o direito é reconhecido e declarado, em atividade preponderantemente intelectiva; naquela é realizado, com transformação do estado de fato. A natureza do litígio é, portanto, diversa num e noutro caso: no primeiro contesta-se a existência do direito; no segundo nega-se a sua satisfação. As lides, para utilizar a terminologia de Carnelutti, são, em decorrência, distintas. ${ }^{29}$ Em segundo lugar, tanto pode haver processo de conhecimento sem subseqüente execução (ação declaratória e ação constitutiva), quanto execução sem prévio processo de conhecimento (execução de título extrajudicial), mesmo no processo do trabalho (CLT, art. 877-A) e, ainda, processo de conhecimento

25. Cf. Jacques Héron, Principes du Droit Transitoire, Paris, Dalloz, 1996, p. 135. 65.

26. Assim, por cxcmplo, Isis de Almcida, Manual da prescrição trabalhista, São Paulo, LTr, 1990, p.

27. TRT - 2" Reg., 3" T., Proc. 37.810/91-6, Rel. Juiz Francisco Antonio de Oliveira in DJSP de 17.12.92. 776.

28. A propósito, Andrea Proto Pisani, Lezioni di diritto processuale civile, Napoli, Jovene, 1994, p.

29. Amplamentc, Sistema di diritto processuale civile, Padova, CEDAM, 1936, pp. 350/35I. 
com simultânea execução (execução provisória de sentença). Em terceiro lugar, evidenciando instaurar-se com a execução nova e verdadeira relação processual, tem início o processo respectivo sempre mediante citação (CPC, arts. 621, 629, 632, 652, etc.), inclusive em matéria trabalhista (CLT, art. 880).

Por tudo isso, proclama-se, sem divergência relevante, a autonomia da ação de execução, fazendo-o tanto a jurisprudência, inclusive a do Supremo Tribunal Federal, ${ }^{30}$ quanto a doutrina, quer a estrangeira, ${ }^{31}$ quer a nacional. ${ }^{32}$ Aliás, mesmo autores mais antigos, mas com espírito mais aguçado, como Ramalho e Almeida e Sousa, já se referiam, em meados do século passado, à execução respectivamente como "um novo juizo" ${ }^{33}$ ou como ação "que nasce da sentença" ${ }^{34}$ E Pontes de Miranda foi enfático, assinalando, mesmo diante da deficiente redação do art. 196, do Código de Processo Civil, de 1939, que parecia conspirar contra a afirmação da autonomia do processo de execução: "a ação de execução de sentença, seja qual for o nome que se lhe dê, ainda que algum legislador de idéias um tanto estapafúrdias redigisse lei em que a execução das sentenças de condenação se colasse à sentença mesma, não desapareceria. Seria o mesmo processo para duas ações! Mais: para duas pretensões, uma das quais somente se faz valer com a sentença sobre a outra. Vestir de calças uma mulher não é fazê-la homem" 3.

30. STF - la T., RE n. 63873/SP, Rel. Min. Aliomar Balcciro, julg. cm 12.09.69 in DJU de 071169.

31. Entrc tantos basta mencionar, como mcra ilustração, Ugo Rocco, Trattato di diritto processuale civile, Torino, UTET, 1959, IV, p. 83, Enrico Redenti, Diritto processuale civile, Milano, Giuffrc̀, 1957, III, p. 101, Salvatorc Pugliatti, Esectzione forzata e diritto sostanziale, Milano, Giuffrc̀, 1935, p. 139, Alsina, Tratado teórico práctico de derecho procesal civil y comercial, Buenos Aires, Compañia Argentina dc Editorcs, 1943, tomo III, p. 43 c Goldschmidt, Derecho procesal civil, Barcelona, Editorial Labor, 1936, p. 538. A proposta cm scntido contrário, de Crisanto Mandrioli, de construção de tcoria unitária da ação c do proccsso, cncontrou rcduzida accitação (L'azione esecutiva, Milano, Giuffrc̀, 1955, passim).

32. Mais uma vez apenas a titulo ilustrativo, cf. Alfredo de Araújo Lopes da Costa, Direito Processual Civil, Rio de Janciro, Forensc, 1959, v. IV, p. 43 c segs., Josć Frederico Marques, Instituições de Dircito Proccssual Civil, Rio de Janciro, Forensc, 1959, v. III, p. 117, Alfredo Buzaid, Do concurso de credores no processo de cxccução, São Paulo, Saraiva, 1952, p. 25, Josć da Silva Pacheco, Ações cxecutivas c cxccução de sentença, Rio de Janciro, Borsoi, 1957, p. 32, Humberto Theodoro Júnior, Curso de dircito processual civil, Rio dc Janeiro, Forcnsc, 1990, v. II, p. 715, Cândido Rangel Dinarmarco, A exccução na Tcoria Gcral do Dircito Processual Civil, São Paulo, s. c. p., 1972, p. 93, Josć Carlos Barbosa Morcira, O novo processo civil brasilciro, Rio de Janciro, Forcnsc, 1993, p. 228 c Araken de Assis, Manual do processo dc cxccução, São Paulo, RT, 1998, p. 96.

33. Praxc brasilcira, São Paulo, Typographia do Ypiranga, 1869, p. 629.

34. Tratado encyclopedico pratico c critico sobrc as cxccuções, Lisboa, Imprensa Nacional, 1865, pp. $16 / 17$.

35. Comentários ao Código de Processo Civil, Rio de Janciro, Forense, 1949, v. VI, pp. 43-44. 
Pois bem, se a execução constitui ação autônoma e distinta, o efeito interruptivo decorrente da citação na ação de conhecimento desaparece com o encerramento desta mesma ação, ${ }^{36}$ nos termos do art. 173, do Código Civil, verbis:

"A prescrição interrompida recomeça a correr da data do ato que a interrompeu, ou do último do processo para a interromper"

Chegando o processo de conhecimento ao seu termo, com o acolhimento da pretensão ou, não-importa, com a celebração de acordo, a prescrição, que se havia interrompido, volta a fluir. Não fica indefinidamente interrompida, porque praticado o último ato do processo, sendo certo que a execução, que poderá ou-não se seguir, constituirá outro processo, e não mero prolongamento do que se encerrou.

Já era assim no direito anterior, das Ordenações do Reino, em que, mesmo não havendo prescrição alguma durante a pendência do processo,$^{37}$ se reconhecia fluir prescrição entre o término do processo de conhecimento e o início do processo de execução, denominando-a Almeida e Sousa prescrição "do direito executivo, que produz a sentença" ${ }^{38}$ Também é assim no Direito Comparado, anotando Chiovenda que "l'actio iudicati è, come ogni azione, prescrittibile" ${ }^{39}$ É ainda assim no Direito brasileiro atual, em que o art. 741, inciso VI, do CPC, consagra exatamente a prescrição da pretensão executiva.

7. Prescrição da pretensão executiva em matéria trabalhista.

Tal como a pretensão executiva nascente de sentença civil, também a pretensão executiva oriunda de sentença trabalhista sujeita-se a prescrição.

É o que se pode inferir da regra do art. $884, \S 1^{\circ}$, da CLT, que, ao tratar dos embargos à execução, estatui:

"A matéria de defesa será restrita às alegações de cumprimento da decisão ou do acordo, quitação ou prescrição da dívida"

A referência a prescrição, no dispositivo transcrito, só pode ser

36. A propósito, Lodovico Mortara, Manuale della procedura civile, Torino, UTET, 1926, Volume Secondo, n. 593, pp. 18-19.

37. Enquanto pendentc a ação, o cfeito interruptivo da prescrição sc prolongava indefinidamente, como mostram os Títulos IX c XVIII, n. 12, das Ordenações Filipinas, no que a doutrina denominava de "pcrpetuação da ação" (Clovis Bevilaqua, Codigo Civil, São Paulo, Francisco Alvcs, 1944, v. I, p. 477).

38. Tratado encyclopedico pratico c critico sobre as cxecuçõcs cit., p. 171.

39. Principii di diritto processuale civile, Napoli, Jovenc, 1965, p. 146. 
interpretada de dois modos: ou indica a prescrição ocorrida antes da propositura da ação de conhecimento ou a prescrição da pretensão executiva, verificada depois de firmada a condenação. Não existe terceira hipótese. Pois bem, diante dessas duas possibilidades de interpretação, a última é a que melhor se ajusta à garantia constitucional da coisa julgada. Admitir pudesse ser suscitada em execução a prescrição ocorrida antes da sentença condenatória diminuiria sensivelmente a estabilidade da coisa julgada, reduzindo em muito o significado do art. $5^{\circ}$, inciso XXXVI, da Constituição ${ }^{40}$ Só isso já é suficiente para que, de acordo com o critério de interpretação conforme à Constituição, ${ }^{41}$ se prestigie solução interpretativa em que a prescrição passível de argüição em execução passa a ser a relacionada apenas com a própria pretensão èxecutiva. Conforme consignado pela Suprema Corte norte-americana, em American Power \& Light Co. v. Securities \& Exchange Commission, de 1946: "Wherever possible, statutes must be interpreted in accordance with constitutional principles" 42

Exata, pois, a observação de Coqueijo Costa, no sentido de que " $a$ execução, que é ação, também prescreve, mesmo na Justiça do Trabalho" " 43 na linha de expressivos precedentes, dos quais se cita, a título ilustrativo, o seguinte:

"O processo de execução é autônomo em relação ao processo de conhecimento e se inicia a partir do trânsito em julgado da decisão cognitiva. O direito

40. O Tribunal Supcrior do Trabalho tcvc ocasião de considcrar o ponto, fazendo-o nos scguintcs termos: "Sc da parte dispositiva da decisão excqücnda não constou a limitação prescricional, ć vedado o scu acréscimo na fasc de cxccução, sob pena de ofensa à coisa julgada"(TST - SDI, ROAR n. 602/89, Rcl. Juiz Convocado Marco Aurćlio Giaomini in DJU de 06.07.90, p. 6.555).

41. É vasta a bibliografia sobrc a interpretação conforme à Constituição, tcma que cscapa completamentc ao âmbito do presente cstudo. Basta mencionar, cntrc as obras que cuidam do assunto, mesmo não sendo específicas, Konrad Hesse, Elcmentos de Dircito Constitucional da Rcpública Federal da Alcmanha, Porto Alcgrc, Scrgio Fabris, 1998, p. 70 c scg., Karl Larcnz, Mctodologia da Ciência Juridica, Lisboa, Calouste Gulbenkian, 1983, p. 416 c ss., Karl Engish, Introdução ao pensamento jurídico, Lisboa, Caloustc Gulbenkian, 1988, p. 147 c ss., Jorgc Miranda, Contributo para uma tcoria da inconstitucionalidade, Coimbra, Coimbra Editora, p. 250 c, postcriormente, do mesmo autor, Manual de Dircito Constitucional cit., tomo II, p. 264 c ss., alćm de Andrć Tunc c Suzannc Tunc, Sistème constitutionnel des États-Unis d'Amérique, Paris, Domat Montchrestien, 1954, IJ, p. 290, nesta última obra havendo vasta indicação de precedentes da Corte Suprema nortc-americana.

42. 329 U.S. 90. Antes dessa decisão, cm U. S. Ex Rel Attorney General v. Delaware \& Hudson Co, 213 U.S. 366, de 1909, a mosma Suprema Corte norte-americana assentou: "It is elementary when the constitutionality of a statute is assailed, if the statute be reasonably susceptible of two interpretations, by one of which it would be unconstitutional and by the other valid, it is our plain duty to adopt that construction which will save the statute from constitutional infirmity"

43. Dircito Processual do Trabalho, Rio de Janciro, Forense, 1984, p. 232. 
do autor à execução é prescritivel (CLT, art. 884, $\$ 1^{\circ}$, da CLT)"'(TRT 2" Reg., $5^{\prime \prime} T$., AP n. 35460/90, Rel. Juiza Maria Doralice Novaes). ${ }^{44}$

Não custa notar que o fato de poder a execução trabalhista instaurar-se de ofício (CLT, art. 878, caput) não prejudica em nada o que se disse. O que interrompe a prescrição é a efetiva propositura da ação, com citação do réu. A mera possibilidade de instauração da relação processual, se não se transforma em ato, não se concretizando, nenhum efeito produz.

9. Prescrição da pretensão executiva e prescrição intercorrente.

A afirmação da prescritibilidade da pretensão executiva trabalhista, formulada no item anterior, não estaria em contradição com os termos do Enunciado $n$. 114, do Tribunal Superior do Trabalho?

Muito se tem criticado a orientação inscrita no Enunciado n. 114, ${ }^{45}$ contestada inclusive por parte expressiva da jurisprudência, ${ }^{46}$ inclusive do Supremo Tribunal Federal, cuja Súmula n. 327 adota orientação diametralmente oposta. ${ }^{47}$ Como quer que seja, a prescrição da pretensão executiva, mencionada no art. $884, \S 1^{\circ}$, da CLT, nada tem com prescrição intercorrente.

Com efeito, intercorrente é a prescrição que se verifica durante a

44. Revista LTr 58-09, p. 1.071. Sempre no mesmo sentido: "O reclamante tem prescrito scu dircito de executar a ação quando permanecc incrte, deixando transcorrer mais de 2 (dois) anos sem promovêla"(TRT 1a Reg., 4a T., AP n. 1.999/85, Rcl. Juiz Joaquim Ignácio Morcira) c "Não tendo ínício a cxecução no prazo de dois anos contados do trânsito em julgado da dccisão, opcra-sc a prescrição pura c simples, da execução"(TRT - 9a Rcg., AP n. 178/84, Ac. n. 10/85, Rcl. Juiz Gcorgc Christófics)

45. Cf. Mozart Victor Russomano, Comentários à CLT, Rio de Janciro, Forcnsc, 1985, pp. 59-60, Arnaldo Sussekind, Délio Maranhão c Segadas Viana, Instituições de Dircito do Trabalho, Rio de Janciro, Freitas Bastos, 1987, vol. II, pp. 1.233-1.234, Valentin Carrion, Comentários à CLT, São Paulo, Saraiva, 2000, p. 78, Wilson de Souza Campos Batalha c Silvia M. L. Batalha de Rodrigucs Netto, Prescriçào c decadência no Dircito do Trabalho, São Paulo, LTr, 1998, p. 47 c Eduardo Gabricl Saad, Dircito Proccssual do Trabalho, São Paulo, LTr, 1998, p. 124.

46. Confiram-se os seguintes paradigmáticos acórdãos: "A Súmula n. 114 do C. TST cncontra-sc cm dissonância com a doutrina dominante, bem como com a Súmula n. 327 do C. Supremo Tribunal Federal...Prescrição intercorrente admitida"(TRT - 15a Reg., 4a T., AP n. 2.024/94, Rcl. Juiza Iara Alves Cordeiro Pacheco in Revista Genesis, junho de 1996, p. 887) c "É aplicávcl à Justiça do Trabalho a prescrição intercorrentc. A lei não se revoga por entendimentos jurisprudenciais"(TRT - 2a Rcg., 8a T., AP n. 24.575/85, Rel. Juiz Valentin Carrion in Revista LTr 52-5/566).

47. Dispõe a Súmula n. 327, do Supremo Tribunal Federal: "O dircito trabalhista admite a prescrição intercorrente".

48. Alice Monteiro de Barros, Aspectos jurisprudenciais da prescrição trabalhista in Curso de Dircito do Trabalho - Estudos cm Memóri dc Célio Goyatá, São Paulo, LTr, 1993, v. I, p. 201. 
tramitação da ação.$^{48}$ Extinto o processo, com o acolhimento do pedido ou a celebração de acordo, não há mais possibilidade de prescrição intercorrente. Não há mais ação em tramitação. Por isso, não cumprindo o reclamado a obrigação que lhe é imposta, se não é, mesmo assim, ajuizada a ação de execução - que é ação diversa, e não mero prolongamento da ação de conhecimento, como se buscou evidenciar acima, no item 6 -, pode verificar-se não a prescrição intercorrente, mas a prescrição da pretensão executiva, prescrição pelo transcurso do lapso de tempo entre uma ação (de conhecimento) e outra ação (de execução), algo completamente diverso de prescrição no curso de uma mesma ação. ${ }^{49}$ A diferença já foi bem evidenciada em decisões que enfrentaram com todo acerto o tema, como a que se reproduz abaixo:

"Na sistemática atual do processo, a execução é uma ação, tragável pela ocorrência prescricional. O caso não é de prescrição intercorrente, mas de prescrição do próprio remédio jurídico, como prevê o art. 884 da CLT" (TRT 5" Reg., I" T., AP n. 808/86, Rel. Juiz Rosalvo Torres)..$^{\text {so }}$

Como se vê, a diretriz firmada no Enunciado n. 114 não-prejudica em nada a afirmação de que a pretensão executiva sujeita-se a prescrição. E tanto é verdade que nada obsta acolha o sistema jurídico a prescrição da pretensão executiva, sem que dê guarida à prescrição intercorrente. Foi o que ocorreu, inclusive, no direito anterior, das Ordenações do Reino, em que, como já mencionado, não prescrevia a pretensão ajuizada, o que nunca impediu o reconhecimento da prescritibilidade da pretensão

49. A resposta à indagação de Manocl Antonio Tcixcira Fillho ("sc não ć a intercorrente, cntão de que prescrição se trata a que $o$ \$ lo do art. 884 da CLT permite o devedor alcgar no ensejo dos cmbargos que vicr a oferecer á cxccução?" in Exccução no proccsso do trabalho, São Paulo, LTr, 1998, p. 269) ć, portanto, bastante simples: a prescrição a que alude o art. $884, \S 1$ lo, do art. 884 , da CLT, ć a da pretensão cxccutiva. Nada mais.

50São Paulo, LTr, 1998, p. 47. Nessa mesma obra encontra-sc ainda o seguinte arcsto: "Agravo de pctição. Prescriçào da cxccução. Não sc confunde prescrição da cxccução c prescrição intercorrentc. Esta sc daria depois de instaurada a cxccução $\mathrm{c}$ não tem sido acolhida pela jurisprudência. Aquela decorre da inćrcia do Excqüentc que, após o trânsito $\mathrm{cm}$ julgado da sentença, não $\mathrm{sc}$ interessa $\mathrm{cm}$ dar início ao processo de cxecução..."(TRT - 15a reg., 4a T., Proc. n. 9.834/95, Rcl. Juiza Iara Alves Cordciro Pacheco). Vale mencionar igualmentc outra decisão "A prescrição da ação de cxccução traballhista, que não se confunde com a prescrição intercorrentc, cstá escrita no $§ 1$ " do art. 884 da CLT...."(TRT - 2" Rcg., 10a T., Ac. n. 02980126858, RO 02970370284-SP, Rel. Juiza Vilma Capato in Bolctim ADCOAS 8160699). Confirasc, finalmentc, o scguinte acórdão: "Prescrição da exccução trabalhista. Incrtc o credor na apresentação dos cálculos de liquidação por 3 anos, cabivcl a prescrição da execução nos termos da Súmula 150 do STF. Tal não destoa do Enunciado n. 114/TST, que trata da prescrição intercorrente (dentro de um mesmo proccsso), pois a prescrição da cxccução ć a superveniente (entrc um c outro processo - cognição c cxccução), como indicam os arts. 884 , §10, da CLT, c 741, VI, do CPC. Por fim, o impulso oficial na cxccução laboral ć faculdade do juizo (art. 878, CLT), assim como a ofcrta de cálculos pela cxccutada ć faculdade desta (art. 605, CPC), que podc também aguardar o prazo da prescriçăo cxccutiva"(TRT - 15a Rcg., 4a T., Ac n. 42.253/2000, Rel. Flávio A. de C. Cooper in DJSP de 06.11.2000, p. 37). 
executiva. É preciso, pois, não confundir prescrição intercorrente com prescrição da pretensão executiva.

8. Prazo de prescrição da pretensão executiva trabalhista.

Antes de concluir é preciso, depois de haver firmado que a pretensão executiva, mesmo emergente de sentença trabalhista, sujeita-se a prescrição, indicar o prazo em que isso se dá.

No Direito comum encontram-se duas soluções. Uma consiste na aplicação, à pretensão executiva, do prazo geral estabelecido no art. 177, do Código Civil, para as ações pessoais. Outra na aplicação do mesmo prazo estabelecido para a pretensão do direito que motivou o ajuizamento da ação condenatória. A primeira solução, que prepondera em doutrina, ${ }^{51}$ não prevalece em jurisprudência, havendo a Súmula n. 150, do Supremo Tribunal Federal, firmado:

\section{"Prescreve a execução no mesmo prazo de prescrição da ação" 52}

A diretriz consagrada na jurisprudência do Supremo Tribunal Federal é a que melhor se harmoniza com a legislação trabalhista, em que a prescrição é estabelecida por norma constitucional, com fixação de prazo de caráter geral, idêntico para os mais diversos direitos e pretensões, variando apenas em função da subsistência ou-não do contrato de trabalho. Assim, a regra do art. 177, do Código Civil, que leva parte da doutrina a sujeitar a prazo mais longo a prescrição da pretensão executiva em Direito comum, tem como correspondente, em matéria trabalhista, o art. $7^{\circ}$, inciso XXIX, da Constituição. Daí que, prazo diverso do fixado pela Constituição, mesmo quando expressamente mencionado pelo legislador ordinário, não pode prevalecer, consoante já teve ocasião de ressaltar a jurisprudência. ${ }^{53}$

Em conseqüência, não se verificando o adimplemento espontâneo da

51. CF., por excmplo, Liebman, Embargos do cxecutado, São Paulo, Saraiva, 1952, p. 167, Pontes de Miranda, Comentários ao Código de Processo Civil cit., p. 43, Chiovenda, Principii di diritto processuale civile cit., p. 146, Lodovico Mortara, Manuale della procedura civile cit., Volume Secondo, 11. 593, p. 18, c Almcida c Sousa, Tratado encyclopedico pratico c critico sobrc as cxccuções cit., p. 171.

52. Na linha da jurisprudência sumulada, Carlo Fadda, Sopra un altra pretesa novazione processuale em Rivista di diritto commerciale, v. VII, 1909, pp. 125-127 c, na litcratura nacional, Amílcar dc Castro, Comentários ao Código de Processo Civil, Rio de Janeiro, Forensc, 1941, v. X, p. 426, bem como Evaristo de Moraes Filho c Antonio Carlos Flores de Moracs, Introdução do Dircito do Trabalho, São Paulo, LTr, 1993, p. 186.

53. É o que se tem decidido a propósito da prescrição aplicável ao FGTS: "Por tratar-se de crédito de natureza trabalhista, tem o empregado apenas cinco anos para reclamar contra o não-recolhimento de sua 
prestação fixada em sentença ou estabelecida em acordo homologado judicialmente, consuma-se a prescrição da pretensão executiva trabalhista passados dois anos, se não houver contrato de trabalho em vigor, ou cinco anos, na hipótese contrária.

São Paulo, março de 2001.

contribuição, c dois anos após a extinção do contrato de trabalho, conforme disciplina o art. 7o, XXIX, “a”, da CF/88"(TST - 5a T., RR n. 256.477, Rcl. Min. Armando de Brito in DJU de 21.08.98). De modo ainda mais cxpressivo: "FGTS. Efetivamente, toda c qualquer norma legal, com prcvisào de prazo prescricional diferente daquele previsto na Constituição Federal, art. $7^{\circ}$, inciso XXIX, sc antecedente, cstá derrogada; se posterior, ć inconstitucional. Conseqüentemente, neste feito, o dircito de ação cstá atingido pcla prescrição, impossibilitando o acolhimento do pleito. Recurso não provido" (TRT 18"R Ac. N. 0503/94. Rel. Juiz Saulo E. dos Santos in DJGO de 16.05.94 p. 54) c "Prescrição. FGTS. Contribuições. Prescriçào. FGTS. O FGTS ć uma contribuiçào social, de natureza tributária (CF, 149), regendo o prazo prescricional de cinco anos (CTN, 174), limitado a dois anos da rescisão (CF, $\left.7^{\circ}, \mathrm{XXIX}\right)$, contra os quais não rivaliza a disposição hicrarquicamente inferior (L. 8036/90, 23, parágrafo $5^{\circ}$ )."(TRT- 2a Reg., 6a T., RO n. 02980347587, Rel. Rafacl E. Pugliese Ribciro, Ac. n. 02990315424 in DOESP, de 06/07/99). 